\title{
A bacia hidrográfica do Lago Paranoá como Geopatrimônio fundante de Brasília, Brasil: unidade de paisagem referência de cultura e sustentabilidade geográfica
}

\author{
The Lake Paranoá hydrographic basin as the founding \\ geoheritage of Brasilia, Brazil: a landscape unit that is a \\ reference for culture and geographic sustainability
}

Tony Marcelo Gomes de Oliveira, Departamento de Geografia, Universidade de Brasília, Brasil, tonymargoli@gmail.com

(1) https://orcid.org/0000-0002-3176-309X

Valdir Adilson Steinke, Departamento de Geografia, Universidade de Brasília, Brasil, valdirsteinke@@gmail.com

(1) https://orcid.org/0000-0002-8738-6975

Resumo: A Bacia Hidrográfica do Lago Paranoá de Brasília localizada inteiramente na região central do Distrito Federal-Brasil, no domínio do Planalto, sob as zonas de chapadas e abundante hidrografia, condicionantes para acomodar o projeto urbano inovador de Lucio Costa para a capital. Entende-se a bacia como patrimônio geomorfológico por sua relevância ambiental generosa e condicionante para a formação da moderna Brasília. Como questão, partimos: pode, a bacia ser legitimada como paisagem original e matriz, por representar o ambiente geossistêmico complexo e exemplar para a formação da cidade? Como método, buscou-se revisão bibliográfica, comparativo de mapas e imagens em tempos distintos e da imprescindível pesquisa de campo para melhor referendar nosso objetivo em reconhecer a Bacia do Lago Paranoá como paisagem original e base física de relevância fundante para a formação cultural urbana e ambiental da capital tombada do Brasil.

Palavras-chave: Bacia; Geopatrimônio; Brasília; Geossistema; Paisagem; Patrimônio Geomorfológico.

Abstract: The Paranoá Lake Hydrographic Basin of Brasília located entirely in the central region of the Federal District-Brazil, in the domain of the Plateau, under the zones of plateaus and abundant hydrography, conditions to accommodate the innovative urban project of Lucio Costa for the capital. The basin is understood as a geomorphological heritage due to its generous and conditioning environmental relevance for the formation of modern Brasília. As a question, we start: can the basin be legitimized as an original and matrix landscape, as it represents the complex and exemplary geosystemic environment for the formation of the city? As a method, a bibliographic review was sought, comparing maps and images at different times and the essential field research to better endorse our objective in recognizing the Paranoá Lake Basin as an original landscape and a physical basis of fundamental relevance for urban cultural formation and environmental of the listed capital of Brazil.

Keywords: Basin; Geoheritage; Brasilia; Geosystem; Landscape; Geomorphological Heritage.

\section{Introdução}

É permitida a afirmação de que a Bacia do Lago Paranoá, originado no projeto arquitetónico da nova capital pelo represamento do Rio Paranoá, é para Brasília, a proeminência geográfica da paisagem original de maior importância para explicitar a 
evolução do pensamento de ocupação do espaço, sob a luz da ciência, do ambiente e da política. Deve-se considerar que a cidade capital do Brasil surgiu de um embrionário diálogo sustentável, cujo ambiente ou espaço físico receptor, a Bacia Hidrográfica do Lago Paranoá (BHLP), foi reconhecida e apropriada como marca definitiva, a fim de acomodar o projeto inovador de Lucio Costa no Planalto Central brasileiro, agregando nela elementos identitários de afeto e aproximação entre o cotidiano social, dinamizado pelos elementos geomorfológicos modeladores da Bacia.

Assim, é objetivo principal da pesquisa identificar e caracterizar os agentes e processos físicos formadores e atuantes na área da BHLP, como subsídio para a efetivação da proposta que define a Bacia do Lago como uma Unidade da Paisagem referência para a cidade de Brasília.

Portanto, segue pertinente a questão norteadora, como hipótese da pesquisa: a BHLP pode ser reconhecida e legitimada como a Unidade de Paisagem geográfica original e matriz, por representar o ambiente geossistêmico complexo e exemplar na formação urbana da cidade de Brasília?

\title{
1. Referencial Teórico
}

As Unidades de Paisagens se particularizam pelos domínios físicos individuais apresentados pelo clima, vegetação, solos, pelo arranjo estrutural, ou exclusivamente por um desses domínios. Elas apresentam

\begin{abstract}
fronteiras de complexa delimitação (já que têm um espectro taxonômico variado), que ocupam um determinado espaço e certo período de tempo, cuja existência é condicionada pelo funcionamento de seus elementos (Monteiro, 2000).
\end{abstract}

A categoria de análise das Unidades de Paisagem pode ser definida como geossistemas, que são compreendidos como o conjunto de fenômenos naturais físicos e fenômenos antrópicos. Em consonância, atuando aglutinados representam a paisagem transformada ou não pelas ações sociais. Na amplitude do conceito, geossistemas podem ser entendidos como unidades naturais integrais, podendo-se distinguir suas modificações e transformações como resultantes das ações dos diferentes tipos de ocupação (Guerra e Marçal, 2006).

$\mathrm{Na}$ ambientação dos geossistemas, a categoria de análise que melhor acomoda a sua dimensão é a paisagem. Mesmo sendo este um conceito considerado polissêmico, ainda, por vezes, estranho à ciência geográfica moderna, afinal, nos novos tempos, a dinâmica transformadora do espaço, são quase sempre amplamente remodeladas pela ação antrópica. Na evolução do discurso científico geográfico, percebe-se o discurso ambiental "flertando" numa crescente com o discurso discreto e contribuidor da geografia cultural, humanista,

assentadas na fenomenologia, no existencialismo, na retomada da matriz historicista, na subjetividade, intuição, nos sentimentos, na experiência, no simbolismo e na contingência, privilegiando o singular e a compreensão como base na inteligibilidade do mundo real (Brito e Ferreira, 2011). 
No contexto momentâneo o conceito de paisagem se avoluma e é revalorizado, encontrando em Bertrand a sua definição conceitual, como sendo

certa porção do espaço, resultante da interação dinâmica e instável de atributos físicos, biológicos e antrópicos, que, reagindo dialeticamente uns sobre os outros, fazem dela um conjunto único e indissociável, em perpétua evolução (Bertrand, 2004).

As relações e dinâmicas espaciais desses fenômenos são compreendidos, na atualidade, com o estudo da complexidade inerente as organizações espaciais. Assim, Christofoletti

atribui à paisagem a compreensão do espaço como um sistema ambiental, físico e socioeconômico, com estruturação, funcionamento e dinâmica dos elementos físicos, biogeográficos e sociais (1998).

A busca pela análise sistêmica se baliza na ideia de paisagem como totalidade, em que se coadunam natureza original, sociedade e cultura em amplo contexto de variáveis que buscam representar a relação da natureza como um sistema entrelaçado a ação humana. A complexidade das paisagens exige uma profusão de classificações, as quais podem enquadrar-se em três princípios básicos de análise: o princípio genético, o estrutural sistêmico e o memorial histórico, que se homogeneízam numa classificação complexa e dinâmica.

A definição de Unidade de Paisagem tem sido um grande desafio por sua complexidade, pois a interação entre

os diversos atributos do sistema natural e do sistema antrópico permite a identificação dos atributos responsáveis pela dinâmica da paisagem, como também identificar as principais fragilidades ambientais de cada unidade, elemento essencial na gestão do território (Amorim e Oliveira, 2008).

Nesse contexto desafiador, a gestão do território como mecanismo de educação das ações sociais no meio ambiente tem reconhecidamente nos estudos de sustentabilidade interligado ao planejamento, o principal meio de efetivações das

ações no espaço territorial, sejam, por meio de diagnósticos, estudos de impactos, levantamentos físicos territoriais, seja pela análise sócio econômica, enfim, por mecanismos que possibilitem antever quadros futuros de organização territorial (Amorim e Oliveira, 2008).

Tal importância também se reconhece no campo da transdisciplinaridade científica, pois alicerçada em estudos setoriais, integrando domínios físicos aos culturais, respeitando suas marcas únicas que dão identidade ao ambiente físico, permite assinalar em escalas e sinais próprios, categorias específicas facilitadoras para identificação e avaliação de impactos, avaliação de recursos naturais, reconhecimento e mitigação de áreas de riscos, avaliação de vulnerabilidade ao ambiente de toda a natureza.

É notório que a gestão territorial se legitima quando se alimenta e ganha musculatura por meio do diálogo entre ciências, autores e conceitos, possibilitando o ampliar de interpretações e contribuições, sendo prática transformadora que venha garantir uma 
maior equidade da distribuição territorial, direcionando o olhar para a melhoria da qualidade de vida em sua totalidade.

\subsection{O Geopatrimônio}

As paisagens, pelas suas peculiaridades intrínsecas ao arcabouço dos seus componentes, compõem um complexo de estruturas que, uma vez possuindo valores singulares, seja pela sua raridade, beleza, funcionalidade, entre outros, justificam ser, como Patrimônio.

Algumas características de particulares das paisagens resultam da presença de formas de relevo excepcionais, as quais realçam os aspectos relacionados com a gênese e evolução do relevo, enquanto testemunhos geo-históricos da interação de processos endógenos e exógenos, com impacto direto nas peculiaridades que caracterizam a paisagem (Bosetti, 2010).

Para Figueiró et al. (2013) a paisagem traduz uma intensa relação entre a sociedade e a natureza, refletida no fornecimento da estrutura dos elementos materiais, abióticos e bióticos que garantem o regular funcionamento ecológico, e no fornecimento das condições para o desenvolvimento da história do Homem na Terra.

Portanto, o geopatrimônio, considerado, neste texto, compreende o "conjunto de valores que representam a Geodiversidade do território", sendo "constituído por todo o conjunto de elementos naturais abióticos existentes à superfície da Terra (emersos ou submersos) que devem ser preservados devido ao seu valor patrimonial" (Rodrigues e Fonseca, 2008; Rodrigues, 2019).

Portanto, aspectos como originalidade e capacidade de suporte, permitem atribuir valoração e identidade, as quais podem orientar diretrizes legais para a proteção, conservação e manejo dos respectivos territórios, tais medidas consolidadas em planos diretores de uso e ocupação, via a análise geomorfológica, especialmente quando esta é realizada em escala de detalhe cartográfico.

Dessa forma, considerando as premissas do geopatrimônio, é possível afirmar que a Bacia do Lago Paranoá é, para Brasília, a proeminência geográfica da paisagem original de maior importância para explicitar a evolução do pensamento de ocupação do espaço, sob a luz da ciência, do ambiente e da política. Entende-se considerar que a cidade capital surgiu de um pioneiro diálogo sustentável, cujo ambiente ou espaço físico receptor, a BHLP, foi reconhecida e apropriada como marca definitiva a fim de acomodar o projeto inovador de Lucio Costa no Planalto Central brasileiro, agregando nela, elementos identitários de afeto e aproximação entre o cotidiano social, dinamizado pelos elementos geomorfológicos modeladores da bacia.

\section{Materiais e método}

Os procedimentos metodológicos deste estudo, estiveram centrados em três eixos, sendo o primeiro de caráter estritamente documental, no qual se buscou realizar um resgate dos documentos pré-construção da nova capital (Brasília), em registros cartográficos, planos, projetos urbanísticos e arquitetónicos entre outros, que 
pudessem evidenciar a relevância da geografia física (de modo muito explicito a topografia e a drenagem) como elementos naturais do sitio que viria a receber a atual cidade de Brasília.

O segundo eixo foi a articulação destes documentos da pré-existência com aqueles disponíveis após a inauguração da capital, neste caso, se pode destacar a abundância de dados e informações, pois desde 1960 existem muitos dados disponíveis, o que se consolida como uma relevante fonte de pesquisa.

No terceiro eixo é proposta a aglutinação geoespacial de todo material disponível e organizado, bem como da articulação de documentos textuais pré e pós a inauguração da cidade, nesta etapa se evidencia a nova conformação territorial, formada pela represa que deu origem ao Lago Paranoá, formando assim a Bacia Hidrográfica do Lago Paranoá. Na figura 1, é apresentado um fluxograma síntese dos procedimentos metodológicos.

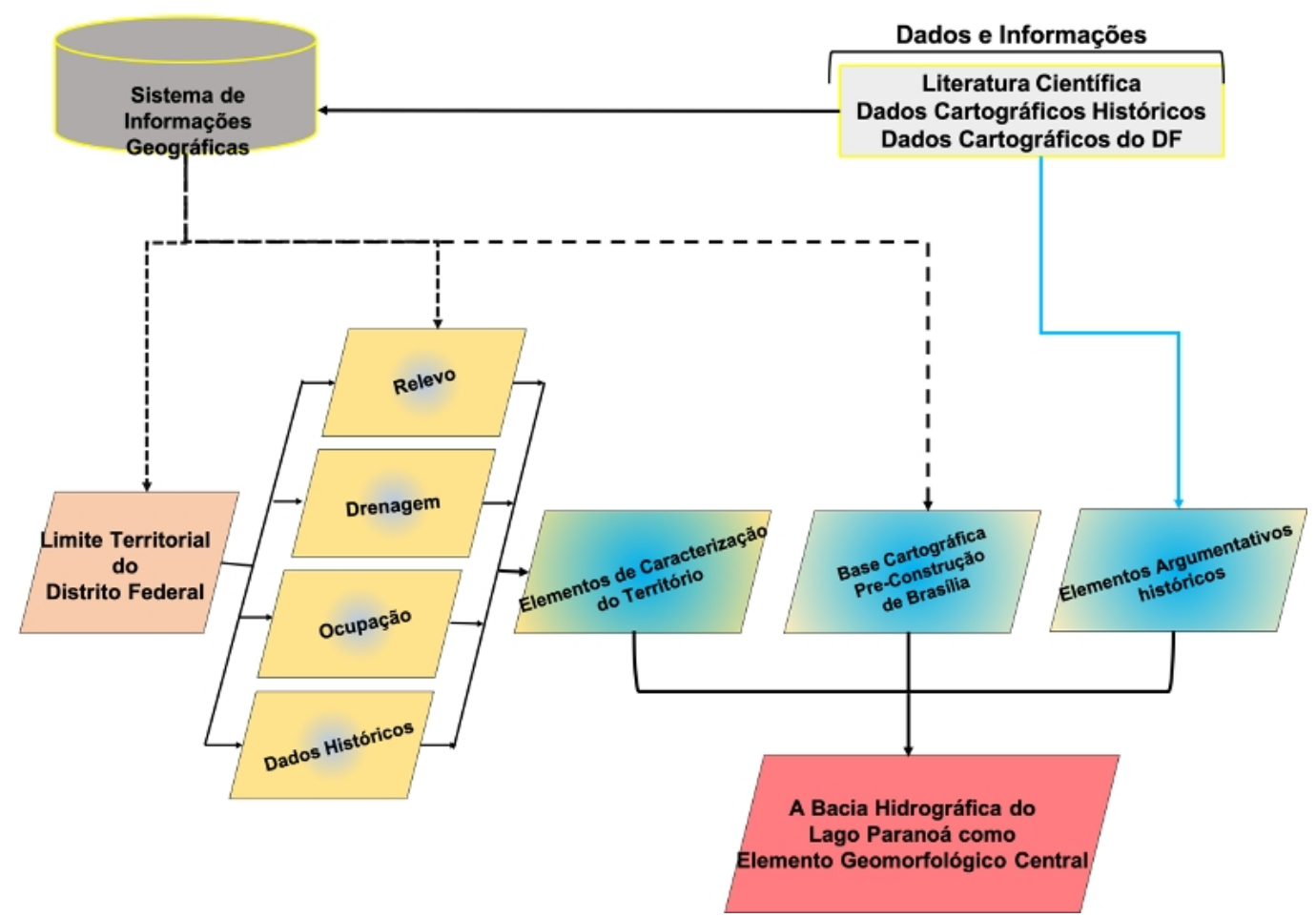

Figura 1: Fluxograma síntese dos procedimentos metodológicos.

\section{3. Área de Estudo}

Localizada na região central do DF (Figura 2), a Bacia do Lago Paranoá (Figura 3) abrange, aproximadamente, uma área de $1.034 .07 \mathrm{Km}^{2}$, tendo em seu domínio o centro da cidade (Plano Piloto) e toda Região Administrativa I - Brasília/Plano Piloto, Granja do Torto, Vila Telebrasília e Vila Planalto, acompanhada em sua borda interna pelas Regiões Administrativas: R.A XVI - Lago Sul; R.A XVIII - Lago Norte; R.A X Guará; R.A XI - Cruzeiro; R.A VIII - Núcleo Bandeirante; R.A XIX - Candangolândia; 
R.A XVII - Riacho Fundo; parte da R.A III - Taguatinga e parte da R.A VII - Paranoá (Geoportal - GDF, 2019).

Limita-se ao Norte com as

Regiões Administrativas de Brazlândia - RA IV e de Sobradinho - RA V (Bacia do Maranhão); ao Leste, com a parte da RA V e da RA VII do Paranoá (Bacia do São Bartolomeu); ao Sul. Com a RA II do Gama (Bacia do Corumbá); e a Oeste, com a RA III de Taguatinga e parte da RA IV de Brazlândia (Bacia do Descoberto) (Fonseca, 2001).

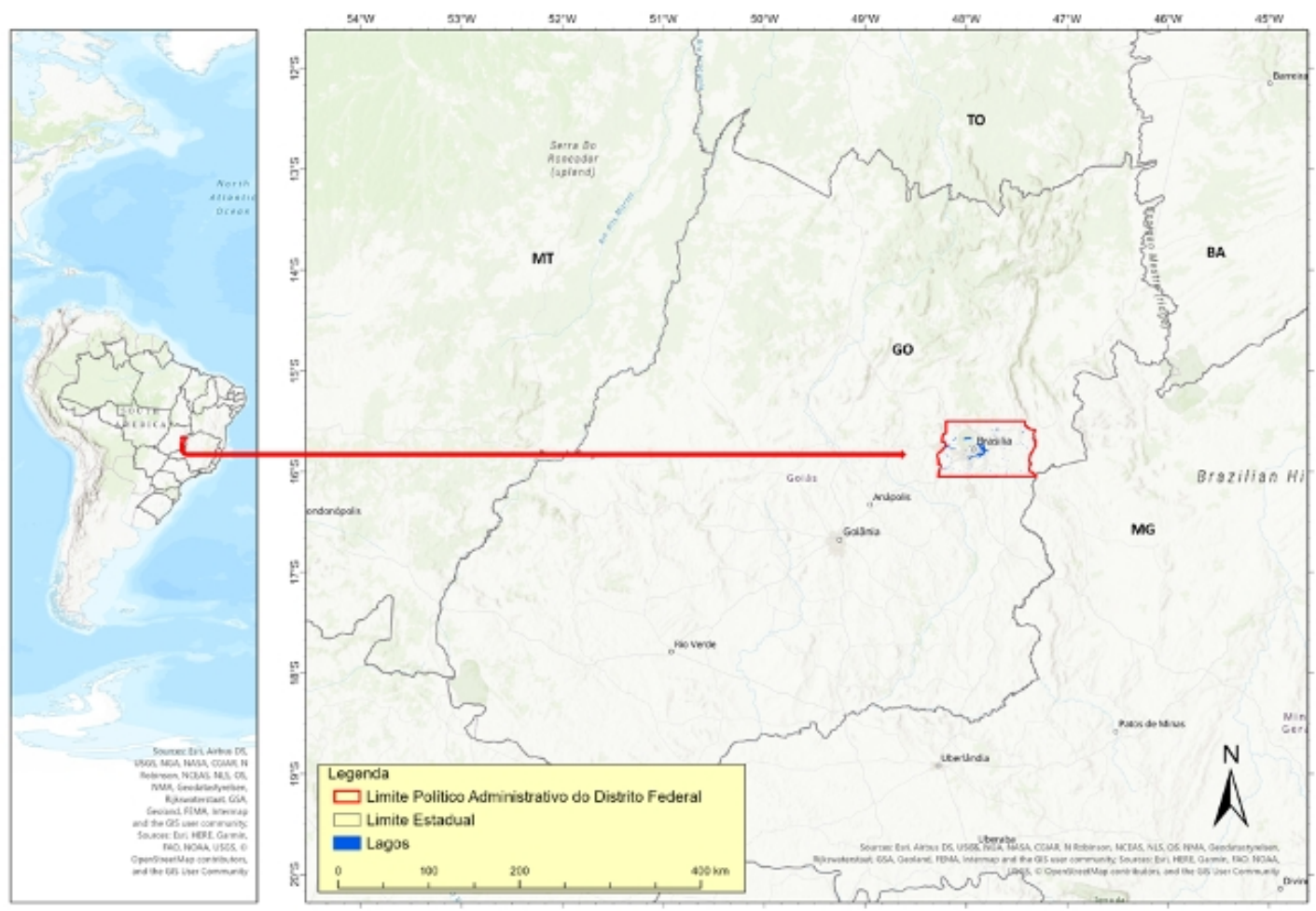

Figura 2: Localização geoespacial do Distrito Federal no Território do Brasil Central. Fonte dos dados: Geoportal GDF (2019). Elaboração dos autores. 


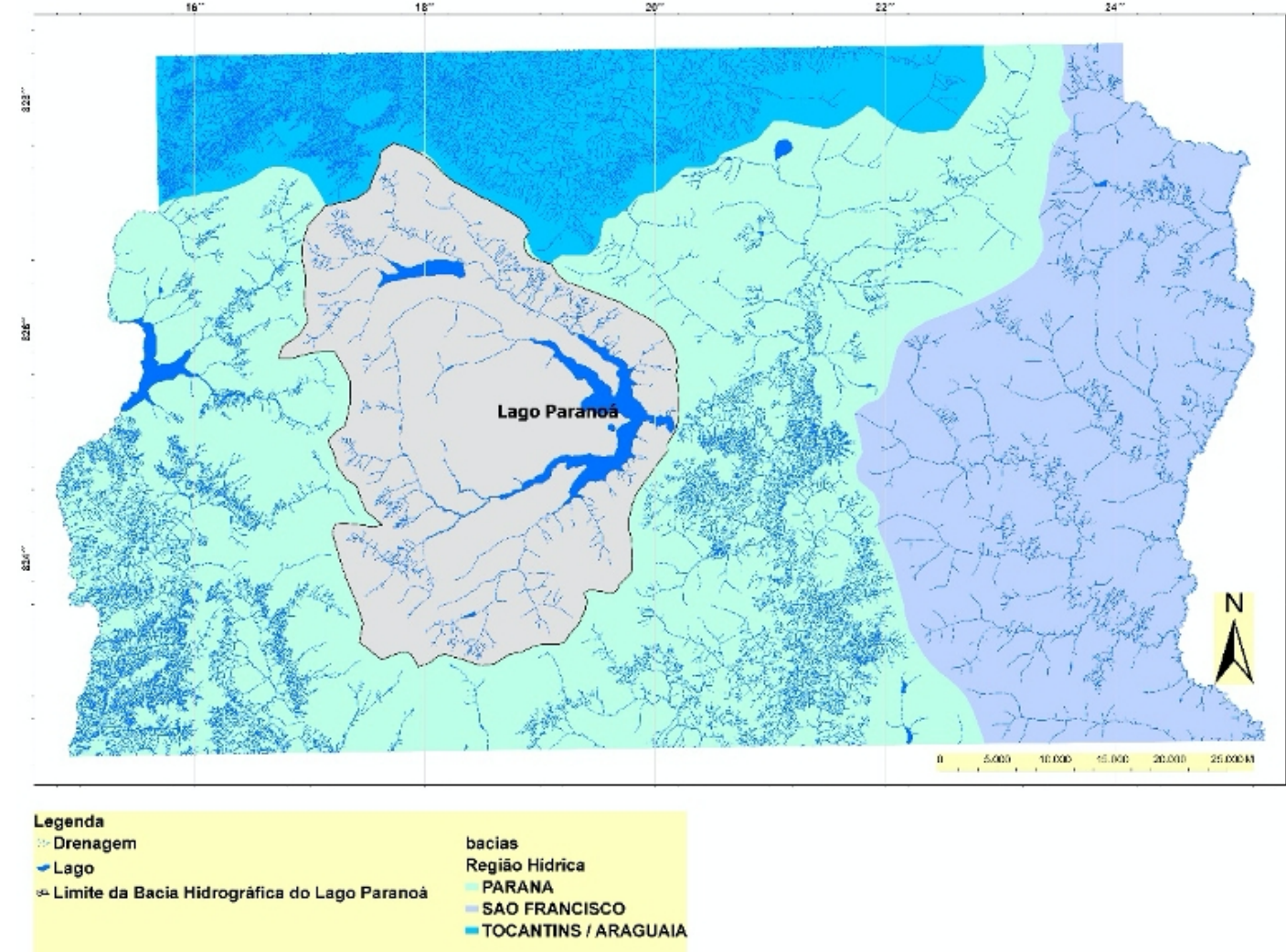

Figura 3: Localização geoespacial da Bacia Hidrográfica do Lago Paranoá no território do Distrito Federal, Brasil.

Fonte dos dados: Geoportal-GDF (2019). Elaboração dos Autores.

A presença de um considerável número de rios tributários, compreende à Bacia do Lago Paranoá uma singularidade em ser a única bacia integralmente localizada em todo DF, possibilitando um diálogo sustentável pioneiro entre ambiente e planejamento, sendo facilitador na observação e controle sobre os mananciais que abastecem o lago símbolo da cidade - Lago Paranoá. Ou seja, o recorte geográfico, objeto da pesquisa, apresenta em sua composição, "todas as nascentes situadas no quadrilátero do DF" (Fonseca, 2001).

A inserção do Lago Paranoá ao plano arquitetónico da cidade teve como mote principal o argumento de proporcionar um microclima local capaz de amenizar as baixas umidades relativas do período seco, que são características dessa região do Brasil Central, bem como a possibilidade de lazer para a população e um pequeno sistema de geração de energia. Especialmente sobre o argumento climático, atualmente não se tem comprovação que surtiu efeito para a cidade.

Vale ressaltar que não era prática comum dentro do planejamento urbano do período moderno a interação direta e dialógica com o ambiente, renegando como prática, a importância da Unidade de Paisagem - bacia hidrográfica - como referência para a construção de cidades. Assim,

O urbanismo modernista tradicional desconsiderou aspectos naturais como esse (bacia hidrográfica) [...]privilegiando o enfoque econômico mais do que nunca. Entretanto, após os anos 70, devido à forte 
presença do movimento ambientalista em nível internacional, a abordagem territorial por meio de bacias começou a se impor e tudo leva a crer que sua adoção é uma questão de tempo (Maricato, 2013).

É interessante observar que antes mesmo do necessário discurso ambiental fazer parte da realidade epistemológica do planejamento urbano, percebe-se que no caso da construção de Brasília, inaugurada em 21 de abril de 1960, práticas e cuidados ambientais foram realizados, antecipando e legitimando o caminho da sustentabilidade no Brasil, visto que, todas as condicionantes adequadas a receber a construção da nova capital, foram definidas pelo estudo de seu ambiente físico, especialmente, pela dinâmica das bacias hidrográficas do DF, dando destaque a Bacia do Lago Paranoá, justo por ser esta a Unidade de Paisagem diretamente ligada ao centro urbano da capital.

Definido o nosso campo de análise e conceitos, de início percebemos que a história da cidade é bem maior e mais valiosa em referenciais informativos de memória. A importância da criação de Brasília mostra-se muito além de sua exuberante arquitetura e de personalismos políticos, comumente evidenciados.

A cidade inaugura em solo nacional o pioneirismo em compromisso com o estudo do ambiente a fim de evitar tragédias, inspirando um novo tempo de relação com o meio físico. O projeto ousado para Brasília pode ser visto como um exercício atento de sustentabilidade já nos anos 50 e ainda experiência em prática do "casamento complicado" entre a geografia física - a bacia hidrográfica como assoalho receptor do Plano Piloto da cidade - e humana, representada pelos ideais mudancistas, desde o século XVIII, contribuindo para um diálogo científico em torno da urbe. Tudo sendo travado concomitante ao surgimento da nova capital brasileira de estética totalmente moderna, porém apropriada de uma trajetória histórica e memórias de desejos políticos e estratégicos, missões de estudos exploratórios em busca de interpretar a paisagem, que datam desde os tempos monárquicos.

\section{A Leitura da Bacia e a doma das águas de Brasília: A Missão de Glaziou}

Valorosas contribuições com a criação de Brasília podem ser referendadas em minuciosos estudos previstos para a sua construção. Ganha destaque a Missão Cruls que nos revela privilegiados pesquisadores participantes, entre eles, aquele que viria a ser o responsável direto pelo "descobrimento" da Bacia do Paranoá, indicando a necessidade de interferência na paisagem com o intuito em fazer ressurgir um grande lago, que proporcionaria, sem dúvida,

além da utilidade da navegação, a abundância de peixe, que não é de somenos importância, o cunho de aformoseamento que essas belas águas correntes haviam de dar à nova capital, despertariam certamente a admiração de todas as nações (Fonseca, 2001,)

O botânico, engenheiro e paisagista da Missão Cruls, Auguste François Marie Glaziou, foi o visionário que interpretou na paisagem um enorme vale que deveria ser espaço ideal para acomodação da nova capital, banhada por um grande lago e delimitada por 
"uma massa forte de serras", combinando condições ideais para o desafio proposto. E define, em seu relatório que

\begin{abstract}
entre os dois grandes chapadões, conhecidos na localidade pelos nomes de Gama e Paranoá, existe imensa planície em parte sujeita a ser coberta pelas águas da estação chuvosa; outrora era um lago devido á junção de diferentes cursos de água formando um rio Parnauá; o excedente desse lago, atravessando uma depressão do chapadão, acabou, com o carrear dos saibros e mesmo das pedras grossas, por abrir nesse ponto uma brecha funda, de paredes quase verticais pela qual se precipitam hoje todas as águas dessas alturas. É fácil compreender que, fechando essa brecha com uma obra de arte. [...] forçosamente a água tornará ao seu lugar primitivo e formará um lago navegável em todos os sentidos (Fonseca, 2001).
\end{abstract}

No observar da morfologia da Bacia se percebe, em todo seu perímetro, a presença de um divisor de águas composto por um conjunto de chapadas (Contagem, Brasília, Taguatinga, Gama e Paranoá), visto como feição natural delimitadora e facilitadora para o projeto da nova capital federal. Fato esse muito bem aproveitado por Lucio Costa para estruturar e acomodar o desenho urbano do Plano Piloto de Brasília em um sítio forte e com características ideais e incomuns, como:

\footnotetext{
- a massa contínua de chapadas elevadas circunscrevendo um espaço geograficamente bem delimitado;

- uma colina de encostas suaves ocupando o centro deste espaço;

- a rede hidrográfica introduzindo linhas de força (os cursos d'água) e elementos naturais de centralização (ponto de confluência dos cursos d'água) e direcionamento (escoamento das águas da bacia por um único ponto, a Leste) (Romero, 2011).
}

\title{
5. Bacias Hidrográficas e Tributários do Distrito Federal
}

Com uma área de $5.789,16 \mathrm{Km}^{2}$, a região do DF é drenada pelas nascentes de três importantes bacias hidrográficas brasileiras: Bacia do São Francisco, tendo o Rio Preto como principal tributário; Bacia Araguaia/Tocantins, abastecidos pelo Rio Maranhão; e Bacia do Paraná, tendo os tributários: São Bartolomeu e Descoberto como os principais contribuidores. De acordo com o mapa hidrográfico do DF,

\begin{abstract}
essas bacias são denominadas de Regiões hidrográficas. Todos os seus rios são de planalto, sendo as principais bacias identificadas por um padrão de drenagem radial. Pela disposição da drenagem, observa-se que dois de seus cursos de água são delimitadores do território do DF: a Leste, o Rio Preto; e, a Oeste, o Rio Descoberto (Fonseca, 2001).
\end{abstract}

$\mathrm{Na}$ análise dos fatos em comparação sóbria é possível considerar a região do DF e o Planalto Central brasileiro como a "caixa d'água" do país, pois são de suas nascentes que escorrem considerável vida hídrica, compondo e dando navegabilidade e funções aos grandes rios nacionais, banhando municípios e sociedades diversas, somando em seguida as águas do Atlântico sul. 
As sub-Bacias hidrográficas do Lago Paranoá são compostas pelas unidades hídricas: córrego Bananal, córrego Riacho Fundo, Ribeirão do Gama, Santa Maria, Torto e o próprio Lago Paranoá.

O centro urbano de Brasília - Plano Piloto - ocupa importante tecido geomorfológico do DF, agregando em sua dimensão física as características e necessidades de uma capital federal, acomodada estrategicamente ao chão do lugar.

O lócus urbano nevrálgico da cidade de Brasília é o seu Plano Piloto tombado como Patrimônio Cultural da Humanidade. Todo o seu núcleo está assentado estrategicamente sob o substrato litólito central da Bacia do Lago Paranoá. Sobre ele está contido os principais mobiliários urbanos da cidade, onde se percebe os melhores índices de qualidade de vida do DF, consolidando como uma simbiose possível, respeitosa e dialógica, entre ambientes: natural, representado na Bacia do Paranoá e social/urbano, representando a dinâmica antrópica no centro de Brasília.

Situada entre os paralelos $15^{\circ} 30^{\prime}$ e $16^{\circ} 03^{\prime}$ de latitude sul e os meridianos de $47^{\circ} 25^{\prime}$ e $48^{\circ} 12^{\prime}$ de longitude a oeste, o DF tem como limites naturais, a Leste o Rio Preto e a Oeste o Rio Descoberto; ao Sul e ao Norte do quadrilátero está limitado por dois cortes paralelos fronteiriços a municípios goianos, formadores do complexo metropolitano de Brasília - RIDE - Região Integrada de Desenvolvimento econômico ou AMB - Área Metropolita de Brasília.

A cobertura pedológica e a organização lito estrutural do relevo do recorte definido como a BHLP têm íntimas relações com as possibilidades condicionantes para erguer a capital Brasília no Planalto central brasileiro.

Assim, em localização,

\begin{abstract}
A área do Distrito Federal está compreendida pelo Planalto Central goiano, na qual se encontram as maiores cotas altimétricas da região do Centro Oeste. Em função delas, divide-se a área do DF em quatro compartimentos geomorfológicos: pediplano de Contagem-Rodeador, pediplano de Brasília, depressões interplanálticas e planícies aluviais e alveolares (Oliveira e Peluso, 2007).
\end{abstract}

\title{
6. Padrões de Relevo da Bacia Hidrográfica do Lago Paranoá
}

As características geomorfológicas da paisagem do domínio morfoclimático do Cerrado resultam de enorme interação de regime climático por duas estações bem definidas, com fatores litológicos, edáficos e bióticos.

Do ponto de vista da geomorfologia estrutural, entre os trabalhos realizados para o território do DF, a investigação de Nascimento (2011), é de valiosa contribuição, pois apresenta o embasamento que sustenta o "Domo de Brasília" a partir da composição geológica e sua evolução, evidenciada pela marcante presença das concreções ferruginosas nos topos e bordas elevadas desse domo. Ao observar a hipsometria do DF (Figura 4), fica evidenciado a presença do "Domo de Brasília" e sua configuração geomorfológica que resulta na conformação da BHLP. 


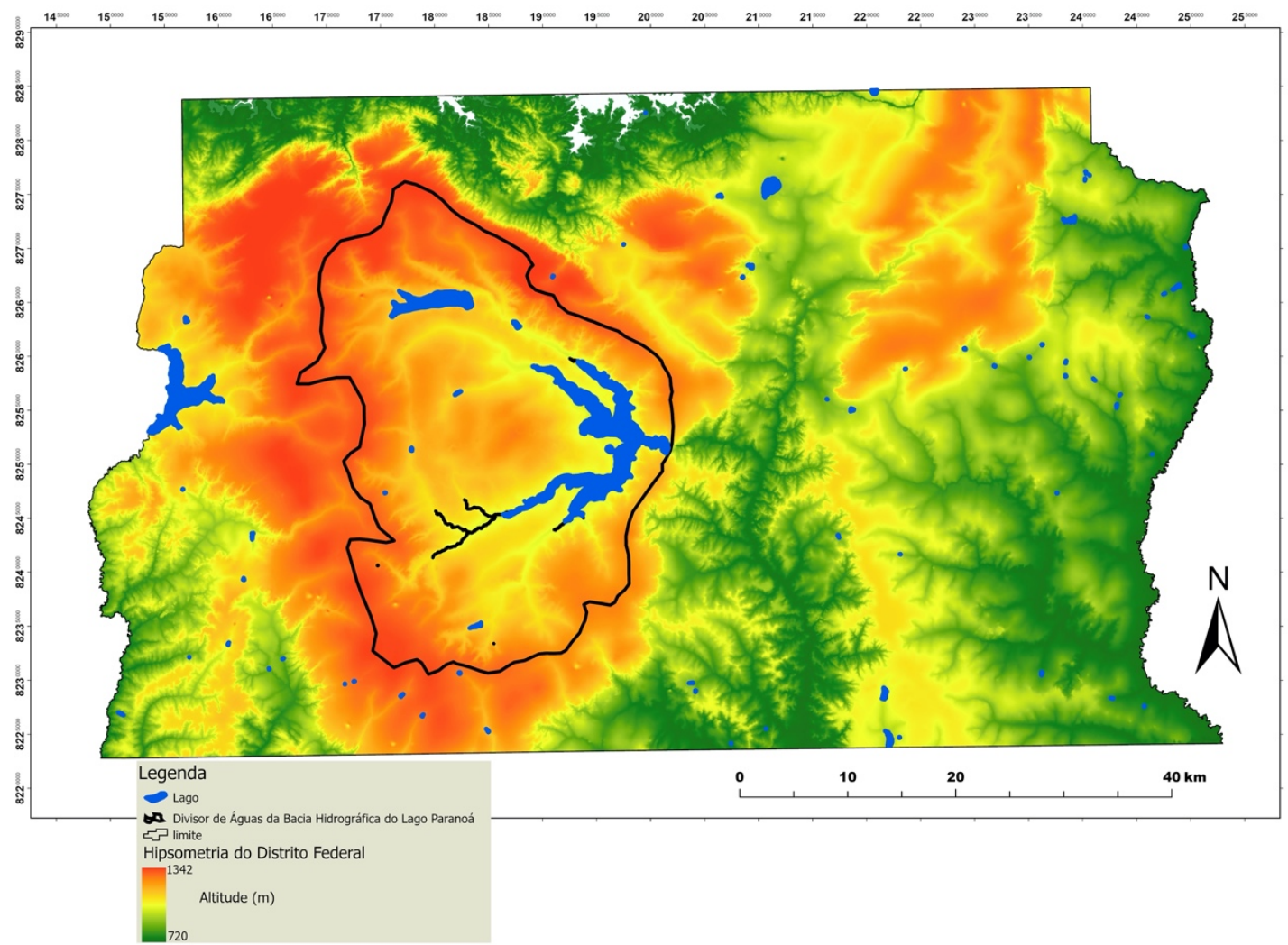

Figura 4: Hipsometria do Distrito Federal, destaque para a Bacia Hidrográfica do Lago Paranoá, com seus divisores de águas delimitados pelo "Domo de Brasília".

Fonte dos dados: Geoportal GDF (2019). Elaboração dos autores.

A cerca da caracterização do relevo do DF, os trabalhos desenvolvidos desde o Relatório Belcher (1957), passando por Penteado (1976), Brasil (1984), CODEPLAN (1984), Maio (1986), Novaes Pinto (1986), Carneiro (1999 e 2001) até Steinke (2003, 2007 e 2011), foram tentativas de aproximação para compartimentação dos padrões de relevo presentes no território do DF. É necessário ressaltar que até este momento esse território não foi mapeado para fins geomorfológicos em escala adequada, especialmente no que diz respeito a sua representatividade histórica e, principalmente, a sua importância para o cenário local.

Tendo como recorte os limites do quadrilátero do DF, dentre os trabalhos realizados, indiscutivelmente o de Steinke (2003 e 2011) busca detalhar em maior nível os padrões de relevo presentes nesta área, inclusa da BHLP. Na qual, para este autor, predominam, padrões de colinas suaves e médias no centro da bacia e as bordas com a presença de morros médios e íngremes (Figura 5). 


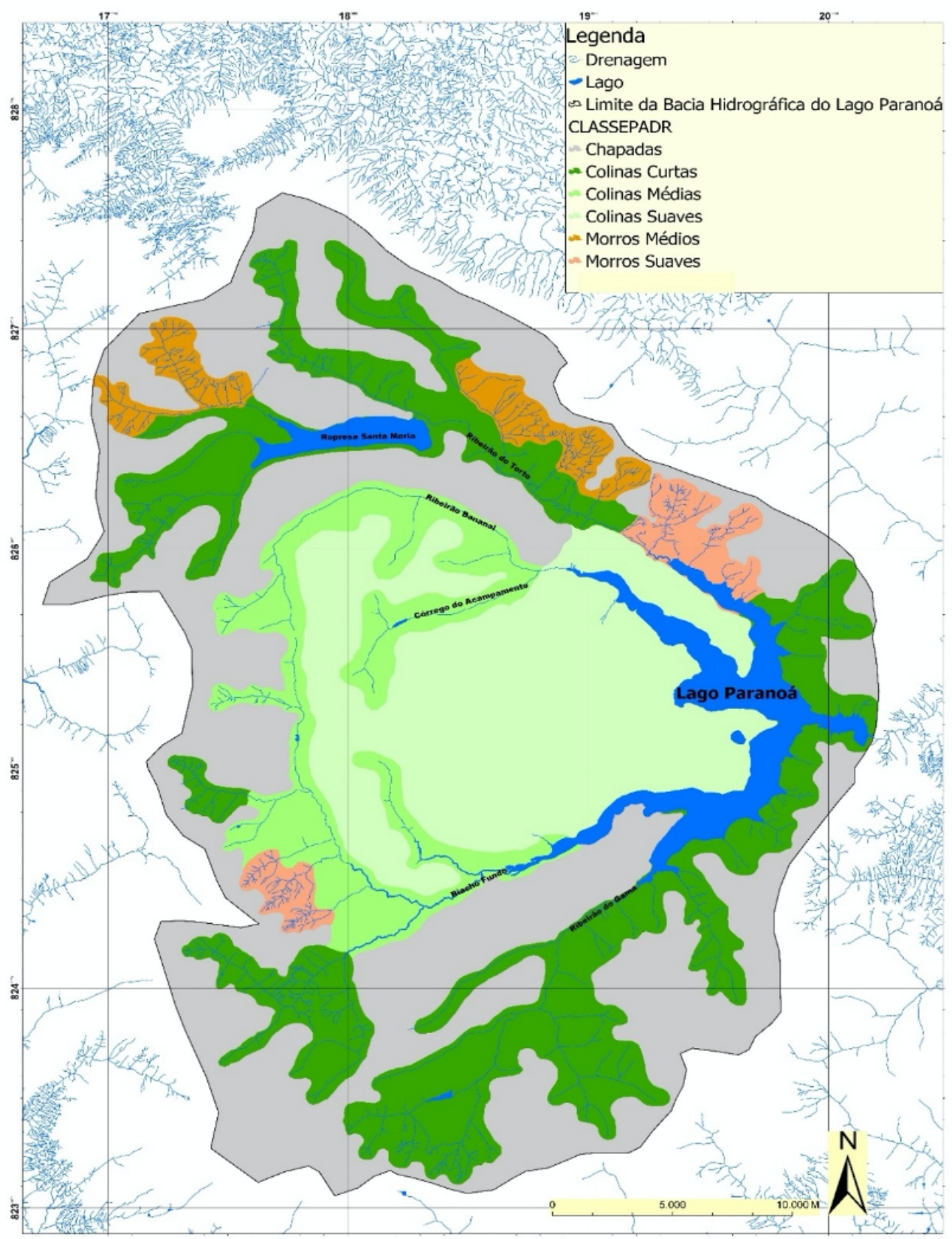

Figura 5: Padrões de relevo para a Bacia Hidrográfica do Lago Paranoá.

Fonte dos dados: Geoportal GDF (2019) e Steinke (2003). Elaboração dos autores.

Sob orientação do método, a análise, a integração e a interrelação entre diversos aspectos e dinâmicas, visando à pesquisa uma maior compreensão crítica e atenta da paisagem, foi permitida a busca da leitura, interpretação e reconhecimento da paisagem da BHLP como uma Unidade (Paisagem) basilar, com características e condições raras e distintas, capazes de acolher em seu leito morfológico, o desenvolvimento sociourbano da cidade moderna de Brasília.

A definição da estrutura geomorfológica na delimitação da paisagem, reconhecendo ser esta uma unidade geossistêmica, só foi possível, considerando o pensamento de 
Ross, em que, "o entendimento do relevo passa, portanto pela compreensão de uma coisa maior que é a paisagem como um todo" (1990). Acrescenta ainda que,

não é possível abranger a gênese e a dinâmica das formas de relevo sem que se entendam os mecanismos motores de sua geração, sem que se percebam as diferentes interferências dos demais componentes em uma determinada Unidade Geoambiental (Ross,1990).

Construindo sempre uma relação de suporte entre tipos e formas de relevo, recursos hídricos, solos e estes com a litologia, tipos climáticos e outros, em dinâmica constante, compondo a geografia ideal para as interferências e ações.

Assim, pelo exposto, é possível reconhecer que a paisagem da Bacia do Lago Paranoá não é formada apenas pela acumulação dos tempos, dos usos, do passado, das ocupações. Ela também é dinâmica e se reproduz na transformação antrópica do espaço pela imbricação dos aspectos culturais e físicos/naturais.

O reconhecimento da BHLP como a Unidade de Paisagem pioneira e generosa para acolher o sonho de construir a cidade de Brasília, eleva ao protagonismo o conceito de paisagem, como categoria de análise geográfica, possibilitando maior significado junto ao planejamento, ao projeto e gestão de espaços urbanos, seja em qualquer escala, assumindo ser ela - paisagem - um produto geográfico, também produtor de práticas sociais cotidianas

A própria morfologia do sítio indicava a acertada escolha do terreno, apontando os caminhos para um possível diálogo sustentável. O recorte geomorfológico e a beleza do Cerrado acrescentaram à cidade dimensão estética e humanizadora, pois se trata de

um sítio convexo. É aberto a todas as influências dos ventos predominantes e, durante os períodos de calmaria, ele tem uma forma topográfica ideal para promover a drenagem do ar [...]. Este vale florestado é de tamanho suficiente e fica a uma distância suficiente para não constituir uma desvantagem (CODEPLAN, 1995).

Ainda sobre a dimensão física da paisagem, Romero afirma que

a configuração (do relevo) que define sua paisagem garante a Brasília a visão de um horizonte de $360^{\circ}$ e da abóbada celeste como um semihemisfério completo (Romero, 2011).

Além dos elementos da paisagem já identificados, outros foram fomentados para ressignificar o espaço, dando visualização e complementaridade ao sítio que receberia a nova capital. Fatos e fatores físicos foram bastante ilustrativos para direcionar o audacioso projeto de Lucio Costa. É fácil perceber que o urbanista

estabeleceu um vínculo com o espaço e escolheu para a localização da capital o triângulo contido entre os braços do lago [...] na linha do espigão, estabeleceu o eixo monumental acompanhando as curvas de nível que descem até o lago e acomodou o eixo rodoviário (Romero, 2011). 
Portanto, na análise do contexto é salutar perceber que, do ponto de vista da ocupação da cidade, o urbanista modernista exigia a manutenção da serenidade da linha do horizonte de Brasília com vista desimpedida sobre a paisagem, formando vínculo de construção de identidade da paisagem cultural na Bacia do lago Paranoá.

\section{Conclusões}

Surge, no presente artigo, como objeto de pesquisa a BHLP, vista como assento principal e de excelência, reconhecida categoricamente como a paisagem original de Brasília. Nela conciliam ecossistemas facilitadores, história e tempos evolutivos, significações, memórias e enormes desafios.

Ingredientes caros e sólidos para embarcarmos no objetivo aqui proposto, onde busca-se compreender a dinâmica da formação do espaço urbano de Brasília, reconhecendo a BHLP como principal marco geográfico e elemento de identidade e afirmação legítimos da cidade capital do Brasil.

É fácil perceber que Brasília, que nasceu sob o signo da modernidade, se evidencia em um sítio generoso e forte, marcado pela presença evolutiva do Cerrado. Concebida para que o aberto e o desimpedido de sua morfologia fosse usufruído democraticamente, a cidade assume seu espaço de identidade entre os meios físicos e antrópicos -, consolidando enraizamentos e pertencimentos em sua dinâmica urbana.

$\mathrm{Na}$ análise dos fatos, é possível afirmar que a BHLP representa para a cidade de Brasília o recorte essencial e condutor principal para o surgimento e realização da cidade capital de todos, levando a crer ser este, o maior desafio de preservação ambiental para uma cidade que nasceu como exercício de sustentabilidade urbana e dotada de alma científica e memória. Dessa forma, a Bacia do Paranoá merece reconhecimento, apropriação, respeito e, sobretudo, cuidados, pois, além de ser o marco definidor para a construção de Brasília, apresenta características naturais e geohistórica ímpares capazes de legitimá-la também como patrimônio geológico/geomorfológico da cidade, do país e do mundo.

De certa forma, vale ressaltar que a BHLP com suas características naturais é o espaço geográfico de memória física da cidade.

Dessa forma, esta pesquisa indica a paisagem da BHLP apropriada e reconhecida como patrimônio geomorfológico local e nacional, por apresentar em sua dinâmica e morfologia, potenciais geomorfológicos, ecológicos, cênicos e identitários, contribuidores para a formação da cidade capital do Brasil, o que aumenta a necessidade de criação e aplicação de estratégias de geoconservação e valorização patrimonial.

\section{Bibliografia}

Amorim, R. R., Oliveira, A. R. C. (2008). As unidades de paisagem como uma categoria de análise geográfica: o exemplo do município de São Vicente - SP. Sociedade e Natureza. Uberlândia, MG, 20(2), 177-198. 
Belcher, D. J. et al. (1957). Relatório Técnico sobre a nova capital da República. Rio de Janeiro: Imprensa Nacional. (Coleção Interiorização da Capital do Brasil, $2^{\mathrm{a}}$ Edição. Brasília: Codeplan).

Bertrand, G. (2004). Paisagem e geografia física global: esboço metodológico. Curitiba, 8, 141-152, Ed. UFPR.

Bosetti, E. P. (2010). Licenciatura em Geografia Geomorfologia 1. Ponta Grossa, Paraná: UEPG/NUTEAD, 2, 87p.

Brasil. Ministério das Minas e Energia. Departamento Nacional de Produção Mineral (19731987). Projeto Radambrasil. Levantamento de recursos naturais. 34 vols. Rio de Janeiro. Folha SD. 23 Brasília: geologia, geomorfologia, pedologia, vegetação, uso potencial da terra / Projeto RADAMBRASIL [v. 29]

Brito, M. C., Ferreira, C. C. M. (2011). Paisagem e as diferentes abordagens geográficas. Revista de Geografia - PPGEO, 2(1).

Carneiro, P. J. R., Souza, N. M. (2001). Compartimentos geomorfológicos do Distrito Federal. Revista Universa. Brasília, 9(2), 339-348.

Carneiro, P. J. R. (1999). Mapeamento geotécnico dos materiais naturais de construção do Distrito Federal: uma base de dados para o planejamento e gestão. Tese Doutorado em Geotecnia - Departamento de Engenharia Civil, Faculdade de Tecnologia, Universidade de Brasília. Brasília, 209 p.

CODEPLAN (1984). Atlas do Distrito Federal. Brasília.

CODEPLAN (1995). O relatório técnico sobre a nova capital da república. Relatório Belcher. $4^{\text {a }}$ ed., Brasília: GDF/CODEPLAN.

Cristofoletti, A. (1998). Modelagem de sistemas ambientais, S.P: Edgar Blücher.

Fonseca, Fernando (Org.) (2001). Olhares sobre o Lago Paranoá, Brasília - DF: Sec. Meio Ambiente.

Figueiró, A. S., Vieira, A., Cunha, L. (2013). Patrimônio geomorfológico e paisagem como base para o geoturismo e o desenvolvimento local sustentável. CLIMEP - Climatologia e Estudos da Paisagem, 8(1-2), 1-24.

GDF - SEDUH - Secretaria de Estado de Desenvolvimento Urbano e Habitação (2019). Disoponível em: https://www.geoportal.seduh.df.gov.br/mapa/\#

Guerra, A. J. T., Marçal, M. S. (2006). Geomorfologia Ambiental. R. J.: Bertrand Brasil.

Maio, C. R. (1986). Alterações ambientais no Distrito Federal, baseadas na geomorfologia dinâmica. Revista Brasileira de Geografia, 48(3), 259-284.

Maricato, E. (2013). Brasil, cidades: alternativas para a crise urbana. 7. Ed. - Petrópolis, RJ: Vozes.

Monteiro, C. A. F. (2000). Geossistemas: a história de uma procura. São Paulo: Contexto.

Nascimento, R. de O. (2011). Evolução de um perfil laterítico em domo estrutural de Sobradinho. Distrito Federal. Tese Doutorado em Geografia, Instituto de Geografia. Universidade de Uberlândia. Uberlândia, $161 \mathrm{p}$. 
Novaes Pinto, M. (1986). Unidades geomorfológicas do Distrito Federal. Geografia, Rio Claro, 11(21), 97-109.

Oliveira, W. C., Peluso, M. L. (2007). Distrito Federal: paisagem, população e poder. S.P: Habra.

Penteado, M. M. (1976). Tipos de concreções ferruginosas nos compartimentos geomorfológicos do planalto de Brasília. Notícia Geomorfológica, Campinas, 16(32), 3953.

Rodrigues, M. L. (2019). Importância do património hidrológico para o geopatrimónio e o geoturismo. In Água e Território: um tributo a Catarina Ramos (pp. 269-278). Lisboa: Centro de Estudos Geográficos, IGOT, Universidade de Lisboa.

Rodrigues, M. L., Fonseca, A. (2008). A valorização do geopatrimónio no desenvolvimento sustentável de áreas rurais. In: VII CIER - Cultura, Inovação e Território. Portugal.

Romero, Marta Adriana Bustos (2011). Arquitetura do lugar: uma visão bioclimática da sustentabilidade em Brasília. $1^{\mathrm{a} e d .}$ S. P.: Nova Técnica Editora.

Ross, J. L. S. (1990). Geomorfologia, ambiente e planejamento. (Coleção: Repensando a Geografia). São Paulo: Contexto.

Steinke, V. A. (2003). Uso integrado de dados digitais morfométricos (altimetria e sistema de drenagem) na definição de unidades geomorfológicas no Distrito Federal. Dissertação Mestrado em Geologia, Instituto de Geociências, Universidade de Brasília. Brasília, 101 P.

Steinke, V. A., Sano, E. E., Steinke, E. T., Nascimento, R. de O. (2007). O Desenvolvimento dos estudos geomorfológicos no Distrito Federal. Geografia (Rio Claro), 32, 107-120.

Steinke, V. A., Sano, E. E. (2011). Semi-automatic identification, gis-based morphometry of geomorphic features of Federal District of Brazil. Revista Brasileira de Geomorfologia, 12, 03-09.

Artigo recebido em/ Received on: 01/04/2020

Artigo aceite para publicação em/ Accepted for publication on: 03/07/2020 